\title{
EUROPEAN STUDENT RESEARCH NETWORK (EUROSURG) IMAGINE PROJECT
}

\author{
Bahadır E. Baki' ${ }^{1}$, Bahar B. Ozkan², Başak Yüksek ${ }^{3}$, Arif Y. Sen ${ }^{4}$, Melik K. Aktas ${ }^{5}$
}

\author{
${ }^{1}$ Karadeniz Technical University School of Medicine, Trabzon, TURKEY \\ ${ }^{2}$ Department of General Surgery, Ankara University School of Medicine, Ankara, TURKEY \\ ${ }^{3}$ Düzce University School of Medicine, Düzce, TURKEY \\ ${ }^{4}$ Dokuz Eylül University School of Medicine, Izmir, TURKEY \\ ${ }^{5}$ Çukurova University School of Medicine, Adana, TURKEY
}

To the Editor,

European Student Research Network (EuroSurg) collaborative was founded by medical students and surgeons at the European Society of Coloproctology (ESCP) congress in 2015 with the aim of running multi-center international studies (1). Due to purpose of collaboration, it has gained active members from many countries all across Europe in very short time.

Turkey is one of the founder members of EuroSurg Collaborative. In the first project called "EuroSurg-1 Major Gastrointestinal Surgery”, EuroSurg Turkey took part with more than 120 collaborators from 20 faculties (2). Projects like these will provide opportunities for medical students in Turkey to take part in an international project and take an important step for their future academic careers. EuroSurg Turkey National Management Team consists of local leads from attending universities.

EuroSurg collaborative provides opportunities for students who are willing to improve research skills, to contribute to international studies. It also supports education for evidence-based research. All collaborators who contribute to EuroSurg projects will gain important research methodology skills throughout the study process (3). All students' names who contribute to EuroSurg projects will be listed as PubMed-citable co-authors.

Postoperative ileus is known as temporary bowel motility dysfunction after abdominal surgery or abdominal trauma. After major abdominal surgery, paralytic period lasts 0-24 hours for the small intestine, 24-48 hours for the stomach and 48-72 hours for the colon. The absence of intestinal motility after these periods is called postoperative ileus (4).
Ileus Management International (IMAGINE) project is a cohort study which will assess postoperative ileus incidence and treatment protocol at different centers around the world. Besides this main aim, this project also focuses on the effects of nonsteroidal anti-inflammatory drugs (NSAIDs) on the recovery of intestinal functions when used for postoperative analgesia, also the safety and risks of NSAIDs (including acute kidney damage and anastomosis leakage) will be assessed (5). People who contribute to this cohort study as medical students, interns, residents will prospectively collect data of patients undergoing elective colorectal surgery over a 14-day period.

EuroSurg Turkey aims for the collaboration of medical students, surgical trainees and consultant surgeons in Turkey and their engagement in international research projects. In this manner, Turkish medical students who are willing to take part in a study will have a more effective role in the medical research world.

\section{REFERENCES}

1. EuroSurg Collaborative. EuroSurg: a new European student-driven research network in surgery. Colorectal Dis 2016;18(2):214-5.

2. Özkan BB, Özbalcı GS, Tavuz Aİ et al. EuroSurg: cerrahide, öğrenci odaklı Avrupa çapında yürütülen alışılmışın dışında yeni bir çalışma grubu. Turk J Surg 2016;32(2):155-6.

3. Chapman SJ, Glasbey JC, Kelly M et al. Promoting research and audit at medical school: evaluating the educational impact of participation in a student-led national collaborative study. BMC Med Educ 2015;13:1547. 
4. Liu S, Carpenter RL, Neal JM. Epidural anesthesia and analgesia,their role in postoperative outcome. Anesthesiology 1995 Jun;82(6):1474-506.

5. Chapman SJ, EuroSurg Collaborative. Ileus Management International (IMAGINE): Protocol for a multicentre, observational study of ileus after colorectal surgery. Colorectal Dis 2018 Jan;20(1):17-25. 